\title{
Editorial: Celebrating Three Year Anniversary and Launching the Seventh Issue
}

As we enter into the fourth year of publishing, the International Journal of Librarianship $(I J o L)$ continues to grow steadily thanks to the support and effort of various librarians and other professionals from the international Library and Information Science (LIS) community. In addition to being included in the Directory of Open Access Journals, IJoL has reached agreement with ProQuest and EBSCO to include all content published by the Journal in their databases to allow wider dissemination of the journal publications.

In the past year, two new issues have been published. This brings the total number of journal publications to 63 which includes 31 Featured Articles, five Reports from the Field, three Commentaries, seven book reviews, three articles on LIS Education Around the World, one Library Associations Around the World article, six Editorial articles, and seven News reports.

In 2020, IJoL will resume the publication of issues on specific topics pertaining to the LIS research and development after a break from publishing special issues in 2019. The Open Journal System will continue to be adopted with an upgrade to its latest version.

\section{In this issue}

Yang, Dawson and Ding at Rider University investigated the promotion of local collections in Discovery Service tools by comparing four major Discovery Service products on market. The findings have implications for libraries to select and implement a Discovery Services.

Through surveys on the use of Virtual Reference Services (VRS) by Chinese students and librarians, Duan at the University of Southern Mississippi explored the international users' satisfaction, familiarity and expectations of VRS in academic libraries in the United States.

In his article, Xuan demonstrated the use of a locally developed system in database usage analysis in Manitoba University Libraries. The Starting Point Uniform Resource Locator logs from EZproxy were adopted for the licensed database usage activity analysis.

At East China Normal University, Guo and Zhu studied their practice of embedded information literacy instruction, including the information literacy courses, instructional models, instructional design, and the use of mobile Internet platform. 
Chen and Joyce explored the most essential knowledge and skills in teaching cataloging and metadata courses by case studying the basic cataloging and metadata class in the LIS program in the University of Hawaii at Manoa.

In the section of Library Associations around the World, Taro Miura outlined the history and organization of the Japan Library Association and how the Association promotes the professional development to librarians in Japan.

Xiaoai Ren reported the 2019 Annual Conference of the Association for Library and Information Science Education (ALISE) in the News section.

Lastly, I would like to thank all colleagues who have contributed to this issue. Wishing everyone a happy and prosperous New Year!

\section{Guoying Liu, University of Windsor, Windsor, Ontario, Canada}

